\title{
Mecanismos constitucionales de manejo de las diferencias constitucionales y descentralización política: asimilacionismo y pluralismo*
}

\author{
Constitutional mechanisms for the management of constitutional \\ differences and political decentralization: assimilationism and \\ pluralism
}

Pavel Humberto Valer Bellota*

\begin{abstract}
Resumen: Este trabajo busca acercarse a algunos puntos teóricos centrales para la comprensión del debate sobre las sociedades multiculturales y la multiculturalidad, en específico respecto a los mecanismos de diferencia étnicas-nacionales, de políticas de acomodación en los diseños con constitución de Estados multinacionales. Asimismo, propone que es necesaria una teoría crítica para desplegar un estudio serio de la constitución política de las sociedades multiculturales, que tome en cuenta que la Constitución puede convertirse en un mecanismo de opresión o liberación de los grupos culturales dominantes y subalternos, respectivamente.
\end{abstract}

Palabras Clave: minorías culturales, multiculturalismo, Estado, Construcción Nacional

Abstract: This paper seeks to approach some central theoretical points for the understanding of the debate on multicultural societies and multiculturalism, specifically regarding the mechanisms of ethnic difference-The European Parliament has also expressed its support for the European Parliament's Green Paper. It also proposes that a critical theory is necessary to carry out a serious study of the political constitution of multicultural societies, take into account that the Constitution can become a mechanism of oppression or liberation of the dominant and subordinate cultural groups, respectively.

Key words: cultural minorities, multiculturalism, State, nation building

\footnotetext{
${ }^{1}$ La redacción de este trabajo ha sido posible gracias a la invalorable colaboración de MAEC-AECID

2 Es investigador en temas de Multiculturalidad, Estado y Derecho. Abogado graduado en la Universidad Nacional de San Antonio Abad del Cusco (Perú). Ha obtenido la Maestría en Ayuda Internacional Humanitaria en el Instituto de Derechos Humanos Pedro Arrupe de la Universidad de Deusto, el Master of Arts in Sociology of Law en el Instituto Internacional de Sociología Jurídica de Oñati, y el DEA en Sociología Jurídica en la Universidad de Zaragoza, es investigador del Laboratorio de Sociología Jurídica de dicha universidad. Correo Electrónico: pavel.valer@unsaac.edu.pe
} 


\section{1.- Introducción}

En toda constitución política se puede advertir la existencia de dos mecanismos propios de manejo de las diferencias culturales, por un lado, se pueden ver elementos de asimilación cultural, y por otro, elementos de pluralismo (jurídico, democrático, emancipador). Estos mecanismos marcan el diseño de la llamada ingeniería jurídica respecto a la acomodación de los grupos culturales no privilegiados por el estado de las denominadas "minorías" culturales.

En el constitucionalismo tradicional, dichos mecanismos o diseños constitucionales establecen jurídicamente relaciones políticas específicas - de dominio o liberación- entre los grupos culturales presentes en el territorio del Estado, asignan legalmente cuotas de poder político a un grupo cultural en desmedro de otros, determinan la manera en la cual se han de resolver las disputas políticas y establecen las preferencias culturales oficiales de un Estado como el idioma oficial, por ejemplo.

Cómo se ha venido discutiendo desde fines de 1960, en el contexto de las relaciones de mayorías y minorías culturales, estos diseños constitucionales están orientados en dos opciones opuestas no siempre excluyentes. Por un lado, se encuentran los mecanismos de asimilación de los grupos culturales "menores" en las sociedades más grandes o más poderosas, o sociedades de los grupos adueñados del Estado, y por otro lado está los enfoques y las técnicas constitucionales pluralistas que buscan otorgar ciertos derechos de autogobierno a las minorías nacionales ${ }^{3}$.

Este trabajo busca acercarse a algunos puntos teóricos centrales para la comprensión del debate sobre las sociedades multiculturales y la multiculturalidad, en específico respecto a los mecanismos de diferencia étnicas-nacionales, de políticas de acomodación en los diseños con constitución de Estados multinacionales. Asimismo, propone que es necesaria una teoría crítica para desplegar un estudio serio de la constitución política de las sociedades multiculturales, que tome en cuenta que la Constitución puede convertirse en un mecanismo de opresión o liberación de los grupos culturales dominantes y subalternos, respectivamente.

\section{2.- Liberalismo y pluralismo étnico-nacional}

La universalización del modelo del Estado-nación, que fue de la mano con la universalización del constitucionalismo, fueron inspirados por la ideología política liberal. Esta Ideología informaba de un mito; que el Estado es imparcial respecto a las expresiones culturales de grupos determinados, que el Estado está impoluto de las expresiones culturales particulares de un grupo étnico-nacional determinado, que las estructuras y fundamentos del Estado están limpias de religión y de valores que fueran más allá de la libertad individual, la intangibilidad de propiedad privada y los demás valores liberales principales. El liberalismo clásico y conservador se ha proclamado de esta manera, por definición, ajeno a cualquier idea de construcción de nación cultural.

Los postulados ideológicos del liberalismo clásico estuvieron generalmente, en teoría, alejados de procesos de construcción nacional, del conjunto de valores, principios, acuerdo y tradiciones que identifican a los individuos de una sociedad política como miembros de una misma nacionalidad o copartícipes de una identidad común ${ }^{4}$.

\footnotetext{
3 Palley, Claire. "Constitucional Law and Minorities”. Internacional Report. Núm. 30. London: Minority Rights Group, 1978.

${ }^{4}$ Ibarra Palafox, Francisco. Minorías etnoculturales y Estado nacional. México: Instituto de Investigaciones Jurídicas, UNAM, 2005, p. 47.
} 
Para esta ideología el proceso de construcción nacional, de cuidado y/o promoción de las manifestaciones de un grupo étnico-nacional no es tarea del Estado.

Sin embargo, el discurso del liberalismo político no puede hacer mucho en contra de la realidad. Todos los Estados que se reclamen liberales se han constituido en la práctica en Estados nacionales (o mejor dicho Estados nacionalizadores) y han abrazado de hecho la idea que se debe promover una sola nación como sustento de identidad entre su población y como único soporte cultural del mismo Estado; en desmedro de otras identidades nacionales o culturales propias de grupos presentes en su territorio pero alejados del poder político, a las cuales han constituido cómo identidades culturales-nacionales "minoritarias".

Ha sido esta actuación de los estados teóricamente y supuestamente neutrales en sus preferencias culturales, pero prácticamente nacionalizadores lo que ha hecho variar el sustento del liberalismo contemporáneo. Asimismo, la constatación de la presencia de diversos grupos étnicos-nacionales en un solo Estado, ya sea de inmigrantes o nacionales subordinadas, y la actuación del Estado que cotidianamente toma decisiones culturales que privilegian las preferencias culturales de determinado grupo apoderado del Estado (como por ejemplo la lengua oficial a ser utilizada, los personajes históricos, las festividades, etc.), ha movido el punto de vista de esta corriente teórica.

Como es sabido, el debate liberal actual ya no pasa por sustentar la neutralidad cultural del Estado, sino más bien por sustentar las razones, el porqué, a los grupos étnico-culturales no dominantes (o no privilegiados por el Estado) se les debería privar de las prerrogativas o facultades de representación cultural que sí tienen las mayorías. ${ }^{5}$ Y, más actualmente, el debate liberal trata de discernir sobre el papel de la ciudadanía en la conformación de democracias estables o más exactamente en la forma en que los derechos diferenciados para las minorías culturales afectan a las virtudes cívicas y prácticas adecuadas de ciudadanía en los Estados democráticos.

En el debate actual se tiene en cuenta que las cualidades y actitudes de los ciudadanos, entre ellas el sentido de lealtad hacia el Estado nacional, su deseo de participación en las instituciones, su capacidad de tolerar y trabajar junto con personas étnicamente diferentes, su deseo de participar en el proceso político, etc., son factores que están en relación directa con la construcción de democracias saludables, sin cuya presencia las sociedades liberales no pueden funcionar adecuadamente. ${ }^{6}$

Kymlicka ha ilustrado claramente los nuevos términos del debate sobre derechos de las minorías y el Estado. Los defensores de los derechos de las minorías han logrado redefinir los términos del debate en dos puntos fundamentales. Primero, que ya son pocos los que aún piensan que la justicia puede ser definida en términos de reglas 0 instituciones ciegas a la diferencia cultural; actualmente es ampliamente reconocido que las normas e instituciones ciegas a la diferencia pueden causar desventajas para grupos particulares. La justicia requiere tanto de normas comunes aplicables a todos como de normas que establecen un trato diferencial de protección y promoción para determinados grupos; estas normas de trato diferencial son algo que debe evaluarse caso por caso en contextos particulares sin ningún supuesto de antemano. En segundo lugar, y a consecuencia del anterior reconocimiento, la carga de la prueba ya no recae únicamente sobre los defensores de multiculturalismo para demostrar que sus

\footnotetext{
${ }^{5}$ Kymlicka, Will. El Nuevo Debate sobre las Minorías. F. Requejo Edit., Democracia y pluralismo nacional. Ariel Ciencia Política. Barcelona, 2002, pp. 25-48, p.35.

6 Kymlicka, Will y Wayne Norman. Citizenship in culturally diverse societies: issues, contexts, concepts. Oxford Univ. Press, 2000.
} 
propuestas de reforma no crean injusticias, sino que esta carga de la prueba es actualmente compartida con los liberales defensores de las instituciones ciegas a la diferencia, quienes deben de demostrar que el status quo no crea injusticias para los grupos culturales minoritarios y sus miembros. ${ }^{7}$

El Estado liberal actual que se precie de ser democrático, pluralista y participativo tiene ante sí el reto de encontrar el mecanismo de convivencia equitativo, adecuado a términos de justicia, con sus minorías etnoculturales; además tiene el reto de promover el diseño democrático de los mecanismos de acomodación política de los grupos étniconacionales presentes en su territorio para promoverles a desarrollar las virtudes que una democracia saludable requiere.

Tratándose de minorías nacionales, se debe comprender que éstas deben de tener los mismos derechos y posibilidades que las mayorías dominantes tienen. Entonces, de lo que se trata es de permitir el desenvolvimiento de procesos de construcción nacional, o nuevos procesos de construcción del Estado; procesos que deben de ser inclusivos y que promoverán la participación democrática de todos los ciudadanos, de sus organizaciones, de los grupos étnico-nacionales a los que pertenecen. Es decir, se debe dotar a las "minorías" culturales de derechos de construcción nacional, de mecanismos legales de nation-building que promuevan su participación política plena en la construcción y dirección del Estado, en la constitución y dirección de sus propios ámbitos políticos regionales en los ámbitos geográficos de su influencia.

No se trata de imponer un tipo de ciudadanía común y homogenizadora a las minorías que se consideran pueblos o naciones distintas al grupo hegemónico, ya que esto no hace más que echar leña al fuego de los conflictos interétnicos. Se trata de dar a las minorías nacionales los mismos derechos que la mayoría tiene por supuestos. Esta no es una tarea sencilla y se ve dificultada por el concepto propio que la construcción nacional tiene en la actualidad y por la realidad política contemporánea que implica a los procesos nacionales con procesos globales.

\section{1.- Dificultades de los procesos de construcción nacional}

Comúnmente, un proceso de construcción nacional (nation-building) se refiere a los esfuerzos que las élites nacionales hacen para crear un estado territorial y movilizar a la población sobre la base de un sentido compartido de identidad cultural. Un proceso de nation-building es más que una simple cuestión de soberanía territorial y la construcción de una "comunidad imaginada". Un proceso de nation-building requiere también, como materia básica, especialmente, las relaciones e instituciones a través de las cuales los bienes son producidos, distribuidos y consumidos con la finalidad de perpetuar las bases materiales y los fundamentos sociales del Estado-nación. En las formaciones sociales capitalistas, el proyecto de nation-building involucra necesariamente interacciones complejas entre el rol de Estado capitalista, el control y el desarrollo de las fuerzas productivas, las relaciones a través de las cuales suceden la producción y el consumo, y las relaciones particulares entre las dinámicas del capital global y la reproducción social sobre una base nacional. Igualmente, tales proyectos están enmarcados en las asimetrías de poder inherentes al sistema interestatal contemporáneo. Por lo tanto, un proceso de nation-building es consecuencia de procesos sociales nacionales y globales a través de los cuales son asegurados y

7 Idem. P.4. 
reproducidos en el tiempo los fundamentos económicos e ideológicos de los Estados nacionales. ${ }^{8}$

La formación del Estado y el proceso de nation-building tienen que ser ubicados en el contexto de la historia de la universalización del sistema del Estado nación, y en la manera como la subsiguiente difusión de la globalización de manera desigual e incompleta, ha empujado a los Estados-nación en muchas partes del mundo hacia los límites de su potencial como medios de seguridad y desarrollo.

Como comenta Berger, los procesos nation-building (o state-building) pueden ser vistos como procesos manejados o facilitados desde el exterior, como intentos de formar o consolidar un gobierno estable, y a veces democrático, sobre un territorio nacional reconocido internacionalmente. Muchas veces, estos procesos se desarrollan en contra del orden político establecido, no obstante, la consolidación de las Naciones Unidas y la universalización de un sistema de naciones-Estados soberanos. El nation-building y el state-building pueden abarcar ocupaciones militares formales, contrainsurgencia, acciones de mantenimiento de la paz (peacekeeping), reconstrucción post conflicto, ayuda internacional, y el uso de la fuerza bajo el auspicio de Estados potencias militares (cómo los Estados Unidos, el Reino Unido, Francia, organizaciones como la OTAN) y otras organizaciones internacionales (ONU). ${ }^{9}$

Por lo tanto, los procesos de nation-building se ven influidos por fuerzas políticas e intereses no sólo de ámbito estatal, o político sino de naturaleza económica; no sólo por elementos nacionales, como las fuerzas políticas o los grupos étnico-culturales, sino por poderes y fuerzas concretas de alcance global. Los procesos de nation-building en la práctica se ven influenciados o a veces determinados, más allá de los arreglos constitucionales positivos por otro tipo de procesos metapolíticos o metajurídicos, por la llamada Constitución material nacional o internacional.

Ante el complejo panorama anterior algunos podrían suponer que los proyectos de construcción nacional democráticos, respetuosos de las diferencias culturales, y alternativos a los planes de los grupos culturales dominantes son una tarea por sí destinada al fracaso. Es decir, que los procesos de construcción nacional orientados a constituir un Estado que no privilegie exclusivamente a un grupo cultural dominante, sino que dé lugar a la participación democrática de todos los grupos culturales civilizatorios- no podrían llevarse a cabo debido a que deben orientarse a procesos que están más allá de las posibilidades reales del Estado nacional y de los grupos sociales civiles.

Lo anterior es una posición errónea, es una propuesta ideológica que desarma cualquier intento de otorgar derechos de autogobierno y autodeterminación a las "minorías" nacionales en cualquier Estado. Ante estas posiciones conservadoras y autoritarias cabe la defensa del Estado democrático de Derecho, del estado garantista de los derechos y libertades fundamentales y defensor de los nuevos derechos emergentes como son los derechos de las minorías nacionales y de los pueblos indígenas a la autodeterminación. En fin, cabe la defensa del pluralismo político-cultural como valor fundamental del Estado constitucional y democrático de derecho.

\footnotetext{
8 Taylor, Marcus. "From national development to 'growth with equity': nation-building in Chile, 1950-2000. Third World Quarterly. Volumen 27, núm. 1, 2006, pp. 69-84.

9 Berger, Mark T. "From nation-building: the geopolitics of development, the nation-state system and the changing global order". Third World Quarterly. Volumen 27, núm. 1, pp. 5-25, 2006.
} 
Las posiciones ideológicas conservadoras, sin embargo, han tenido gran difusión y se han configurado como la base teórica que ha fundamentado la práctica histórica de gran parte de los Estados. Esta Práctica se ha basado en las teorías contrarias a los procesos alternativos y anti hegemónicos de construcción nacional democrática y participativa, y tienen su base en los conceptos de asimilacionismo.

\section{2.- El asimilacionismo}

Desde una visión histórica se puede decir que la idea de Estado-nación se sustentó durante largo tiempo en la creencia de que los límites étnicos culturales no deben contraponerse a los límites políticos, esta idea se tradujo en el principio de las nacionalidades: "cada Estado una nación, cada nación un Estado". Dicho principio tiene tres consecuencias (1) se considera que nación unidad cultural esencialmente homogénea; (2) se concibe a la nación como una entidad soberana donde residen y desde donde emanan todos los poderes del Estado, una soberanía que no es divisible y que se corresponde con todo el territorio nacional del Estado; (3) se considera que el Estado debe unir bajo una única soberanía, y a partir de una distribución homogénea de los poderes territoriales, a la totalidad de la ciudadanía con iguales derechos. ${ }^{10}$

Ese ha sido el modelo clásico de construcción forzada de Estados-nación a lo largo de la historia, un modelo al que Ramón Maíz denomina Estado nacionalizador caracterizado por considerar que el Estado está al servicio de una nación específica. Dicho modelo considera que la nación privilegiada por el Estado, su lengua, su posición demográfica, su bienestar económico y su hegemonía política debe ser protegida y promovida por el poder político.

Sin embargo, el modelo político del Estado nacionalizador presenta características sumamente criticables desde un punto de vista democrático; es eminentemente excluyente, hace que la condición de ciudadanía democrática de grandes grupos de la población sea precaria, frágil. Esta ciudadanía de baja intensidad, o simplemente ciudadanía nula, puede afectar, en algunos casos, a las mayorías numéricas en el territorio de los Estados. Las características del Estado nacionalizador son, siguiendo a Maíz, las siguientes:

(1) El estado democrático, la apropiación del Estado por una específica nación étnicamente definida por características orgánicas tales como raza, cultura, lengua y religión.

(2) La escisión entre los ciudadanos nacionales considerados "auténticos" y los "menos residentes permanentes" en el Estado, los cuales, al no pertenecer a la nación oficial, son tratados como "ciudadanos" de segunda clase y sometidos a políticas de normalización lingüística, asimilación y aculturación según los patrones de la nación homogénica.

(3) Estos procesos son guiados por la idea de que la nación oficial no se encuentra aun plenamente desarrollada pese a la posesión de un Estado propio, y que este déficit de homogeneidad y sustantividad nacional debe ser corregido con políticas nacionalizadoras (compensatorias de la discriminación histórica sufrida).

\footnotetext{
10 Caminal Badia, Miquel et ál. Manual de ciencia política. Madrid: Tecnos, 1998.
} 
(4) La regulación política asimilacionista desde el Estado se complementa mediante la movilización política, organizativa e ideológica nacionalista en la sociedad civil, estimulada desde el Estado, como elemento de apoyo y realimentación de las políticas nacionalizadoras.

El Estado nacionalizador se sustenta ideológicamente en las teorías asimilacionistas que postulan la necesidad de la existencia de un proceso en el que el grupo dominante acoge a los miembros de otras culturas y las incorpora a la suya. El modelo asimilacionista se basa en la idea de la necesidad de modificar la conducta de las minorías culturales para adaptarlas a los valores, costumbres y formas organizativas de la sociedad receptora considerada superior. La asimilación es el medio que los estados utilizan universalmente para terminar con el "problema" de las minorías étnicas, dicha asimilación empieza generalmente por la negociación a reconocer el problema: las poblaciones halógenas y sus caracteres particulares son simple y llanamente negados; a nivel estadístico y jurídico queda suprimida toda categoría especial. Si existen algunas diferencias difíciles de negar se las minimiza y desprecia. La destrucción sistemática de los rasgos culturales étnicos es el etnocidio, que llega a cambiar gradualmente el carácter de una población minoritaria integrándola en la etnia dominante a través de la lengua, la religión, la conducta, etc., se trata de una desculturación- aculturación que entraña la desaparición de la etnia. ${ }^{11}$

Adicionalmente, la mayoría utiliza otros mecanismos de dominación por lo que se busca la asimilación mediante la imposición de sus propios estándares (o instituciones) políticas, económicas y culturales. Los mecanismos de dominación se traducen en técnicas que se aplican en los campos político, económico, cultural y de orden público.

En el campo político la mayor técnica empleada es la limitación del poder político de la minoría mediante diversos mecanismos de manipulación electoral, como puede ser la restricción de los derechos ciudadanos de voto de los miembros de las minorías o la prohibición de partidos políticos de la minoría, partidos políticos regionales o la limitación de su participación en órganos de poder del Estado (generalmente en el parlamento). Se pueden establecer requisitos de educación, propiedad, ocupación, u otras para poder ejercer el voto, o para impedir que un grupo étnico no privilegiado por el Estado pueda votar. Pueden establecerse requisitos de registro de organizaciones políticas aplicados específicamente a las minorías, restringiéndolas o impidiendo que lleguen a tener representación a nivel estatal. Una medida mucho más drástica es el traslado de la población minoritaria hacia circunscripciones electorales donde no sea considerada un peligro.

En el campo económico, se busca preservar el poder económico de un grupo o son medidas destinadas a remediar lo que el grupo hegemónico consideraba como desbalance o disparidad del poder económico entre los grupos étnicos. Un ejemplo de esto pueden ser las disposiciones relativas a la propiedad de la Tierra. Otro medio es el control del empleo de personal en las dependencias del Estado (funcionarios), o en la empresa privada, asegurando que los patrones de empleo satisfagan las necesidades de los grupos dominantes. Algunas políticas fiscales pueden ser utilizadas también para estos propósitos.

\footnotetext{
${ }^{11}$ Maíz Suárez, Ramón. "Retos contemporáneos de la Política II: Los nacionalismos". En R. Del Águila, et ál. Coord. Manual de Ciencia Política. Madrid: Trotta, 1997, p. 483 (Ejemplos de este tipo de Estado son Estonia, Letonia, Ucrania, Kazakistan, Croacia, Yugoslavia, etc.; y también puede estar el Perú y otros de América del Sur.)
} 
En el campo cultural, es necesaria una investigación de las políticas de la administración pública para descubrir qué normas relacionadas con la cultura son usadas para asegurar la dominación con el objetivo de determinar las incoherencias entre las previsiones legales y la práctica concreta del Estado. Lo que la minoría describe como asimilación forzada es generalmente visto por la mayoría como actos destinados a la preservación de la "identidad nacional".

El idioma es un tema esencial en el campo cultural en los Estados multinacionales. La importancia de los idiomas oficiales es tal que generalmente se necesita hablar un determinado idioma para poder progresar económicamente, o para poder acceder a los servicios del Estado. Con esto, los padres de los niños pertenecientes a grupos étnicos minoritarios tenderán a educar a sus hijos en las escuelas donde se enseñe (o se implante) el idioma oficial, degradando la importancia de su propio idioma.

En el campo del orden público se deben tener en cuenta las restricciones a las garantías y libertades individuales y de grupo. Para mantener el orden público, la mayoría hegemónica puede "crear" una serie de delitos contra el Estado y contra el orden político para mantener las posibles protestas de los grupos no privilegiados dentro de los límites controlables mediante provisiones legales y actividades judiciales. En estas condiciones es anulado o disminuido considerablemente el derecho de resistencia de las minorías culturales en una situación a las que GARGARELLA denomina alienación legal cuando el derecho comienza a servir propósitos contrarios a aquellos que justificaban su existencia. ${ }^{12}$ También puede darse que en el reclutamiento de los miembros de las fuerzas armadas y/o policiales se prefieran a determinado grupo étnico cultural (o económico). El ejército puede ser usado también como mecanismo de asimilación cultural.

El mecanismo de asimilación del Estado nacionalizador puede remitirse también a una cuestión de la construcción de las identidades. ${ }^{13}$ Según Castells, ${ }^{14}$ por un lado existe la identidad legitimadora, que es aquella introducida por las instituciones dominantes de la sociedad para extender y racionalizar su dominación; en segundo lugar la identidad de resistencia, generada por los actores sociales que se encuentran en posiciones o condiciones devaluadas o estigmatizadas por la lógica de la dominación, por lo que construyen trincheras de resistencia o supervivencia basándose en principios diferentes opuestos a los que impregnan las instituciones sociales; y por último, existen identidades proyecto, cuando los actores sociales, basándose en los materiales culturales de que disponen, construyen una nueva identidad que redefine su posición en la sociedad y buscan la transformación de toda la estructura social.

\section{3.- Políticas de supresión de las diferencias étnico-nacionales.}

El asimilacionismo da sustento a las políticas de supresión de las diferencias culturales. Estas buscan la uniformización y homogeneización cultural de todos los ciudadanos bajo un modelo cultural único que se presenta como el modelo "oficial", como la cultura considerada "correcta" por el grupo étnico nacional apoderado del Estado. Más específicamente, las políticas de supresión buscan la eliminación de las expresiones culturales -la supresión de los modelos civilizatorios- de los grupos subordinados. Estas políticas llevadas a cabo por los Estados nacionalizadores se

\footnotetext{
12 Gargarella, Roberto. "El derecho de resistencia en situaciones de carencia extrema". En Astrolabio revista internacional de filosofía. Núm. 4, 2007, pp. 1-29.

13 López Trigal, Lorenzo y Benito del Pozo. Geografía Política. Madrid: Cátedra, 1999.

14 Castell, Manuel. "La Era de la Información". Economía, Sociedad y Cultura: El Poder de la Identidad. Volumen II. Primera Edición en español. México: Siglo XXI editores, 1999.
} 
basan en una lógica política de exclusión que va en contra de la lógica de la democratización, niegan la generalización de los derechos individuales para la ciudadanía, además de renegar de cualquier forma de política inclusiva y de acomodación de las minorías basada en derechos de grupo o colectivos, promoviendo identidades múltiples y complementarias, por completo prescindibles en las modernas sociedades complejas. Las políticas de supresión según Maíz, pueden adoptar las siguientes formas: ${ }^{15}$

a) Asimilación. Fue utilizada ampliamente hasta mediados de la década de 1960, sin embargo, en la actualidad es grandemente criticada. Se trata de una política individualista, en la que la ausencia a la reducción de los derechos colectivos proporciona incentivos positivos y negativos para el abandono de los vínculos étnico-nacionales por parte de las minorías. Junto a ello, los grupos dominantes despliegan un proceso simultáneo de state-building, con la finalidad de que la lengua, cultura y valores de la nación dominante se implanten como normales expresiones "oficiales". La asimilación persigue crear una identidad colectiva común de ámbito estatal, suprimiendo o despotenciando las diferencias subnacionales, incentivando el abandono de la propia cultura y autonomía social de los grupos minoritarios como precio por integrarse en la sociedad mayoritaria.

La asimilación puede asumir dos variedades: las políticas de asimilación propiamente dichas con el objetivo explícito de la eliminación progresiva o la desactivación política de las diferencias nacionales interiores, con vistas a la creación de una identidad étnico cultural común; las políticas de integración dirigidas a la creación de una identidad común cívica y no étnico-cultural (patriotismo). Las políticas de asimilación pueden a veces mostrar algún grado de reconocimiento de las minorías nacionales que pueden ir desde la descentralización administrativa o federalismo atenuado (en caso de minorías territoriales) hasta alguna forma de autonomía cultural o política de base étnico-personal (en caso de minorías no territorialmente concentradas). ${ }^{16}$

Las políticas asimilacionistas pueden ser implementadas desde diversos alcances, en síntesis: 1. En lo cultural, imposición de una lengua oficial en el sistema educativo, en la administración, en los medios de comunicación e incluso en las actividades privadas (comercio, banca, publicidad, etc.) 2. En lo político sobre representación directa o indirecta de la nacionalidad dominante en el gobierno, en la administración del Estado, en los cargos públicos, etc. 3. En el ámbito jurídico: el privilegio en el derecho (privado, civil, penal, etc.) de las instituciones, prácticas y convenciones de la nación o grupo

\footnotetext{
15 Maíz, Op. Cit,. p. 492.

${ }^{16} \mathrm{El}$ autor comentado indica que "Las políticas integracionistas favorecen medidas tendentes a reducir las diferencias políticas y económicas entre las comunidades mediante mecanismos de solidaridad y redistribución, socialización en una lengua común y similares hábitos cívicos, así como contra la segregación en política de viviendas o de trabajo, todo ello en el marco de una concepción de los derechos predominantemente individuales y en ausencia o residual reconocimiento de derechos colectivos sustitos. En este sentido se rechaza, por ejemplo, el trato especial para las minorías, incluida en ocasiones la discriminación positiva o las cuotas, privilegiando criterios de mérito e igualdad de oportunidades, así como se desconsidera cualquier tipo de autogobierno pleno. Las políticas asimilacionistas, son más agresivas e intensas (...) se pretende la no creación de un patriotismo cívico o constitucional, sino la imposición de una identidad colectiva étnico-cultural global (francés, serbia, rusa) con carácter exclusivo, lo que implica la paralela supresión de las diferencias subnacionales. Se basa en dos asunciones problemáticas: Primero, que existe una única cristalización posible -política, cultural e ideológica- de la nación dominante, fundada en a) la sistemática ocultación de las diferencias internas dentro de la propia nación dominante y b) una supuesta continuidad histórica y primordial, inmutable de la esencia nacional a través de los tiempos que enmascara el carácter cambiante y políticamente construido de la misma. Segundo, que una identidad étnico-cultural es por definición excluyente de otras, de tal modo que se ignora la posibilidad real, documentada hasta la saciedad en muy diferentes contextos no fundamentalistas, de la coexistencia pacífica (...) Maíz Suárez, Ramón. Retos contemporáneos de la Política...p. 491.
} 
étnico dominante. 4. En lo económico: trato preferencial de empresas, subvenciones y privatizaciones a favor de las élites de la nación hegemónica.

b) Limpieza étnica. Son políticas que implican la expulsión o migración de minorías nacionales, con abandono forzado del territorio de su residencia tradicional (que puede ser de siglos), destinadas a eliminar la diferencia interna para construir una nación única y homogénea. El abandono del territorio se logra mediante la presión cultural, social, activa o pasiva del Estado nacionalizador, con políticas de "normalización", ostracismo, discriminación, y otras sobre los miembros de la nación minoritaria, para aclarar así el espacio nacional a favor de los "auténticos nacionales" y de quienes aceptan resignadamente la asimilación y la aculturación renunciando a su patrimonio cultural. ${ }^{17}$

c) Genocidio. Esta Estrategia se sitúa en el extremo continuo de políticas de limpieza étnica, es la exacerbación del desarrollo de dichas políticas que asumen la forma del determinado tipo de actos criminales perpetrados con intención de destruir, total o parcialmente, a un grupo nacional, étnico, racial o religioso como tal. Su tipificación básica se encuentra en el artículo $2^{\circ}$ de la Convención para la Prevención y la Sanción del Delito de Genocidio de las Naciones Unidas. Esta convención fue adoptada por unanimidad el 9 de diciembre de 1948 y entró en vigor el 12 de enero de 1951. El genocidio es un crimen contra la humanidad, su definición se recoge de la Convención de los Estatutos de los tribunales penales internacionales ad hoc para la antigua Yugoslavia (1993) y para Ruanda (1994) y en el Estatuto de la Corte Penal Internacional (1998). Así, se entiende por genocidio cualquiera de los actos siguientes, "perpetrados con intención de destruir, total o parcialmente, a un grupo nacional, étnico, racial o religioso como tal": a) Matanza de miembros del grupo. b) Lesión grave a la integridad física o mental de los miembros del grupo. c) Sometimiento intencional del grupo a condiciones de existencia que hayan de acarrear su destrucción total o parcial. d) Medidas destinadas a impedir los nacimientos en el seno del grupo. e) Traslado por fuerza de niños del grupo a otro grupo. ${ }^{18}$

\section{3.- Técnicas constitucionales pluralistas.}

De manera contraria a las políticas de asimilación, los mecanismos pluralistas buscan respetar y mantener las diferencias culturales. Desde un punto de vista de desarrollo democrático, el pluralismo admite las diferencias culturales y las valora positivamente, considera la existencia de un derecho a la diferencia cultural. Esto porque el pluralismo surgió vinculado a la escuela filosófica que se opone al Estado absoluto y soberano, al Estado in

contestable, ya que se supone que éste no se ajustaba a la realidad empírica ni era deseable como objetivo normativo. El pluralismo describe una situación en la que el poder político se distribuye entre una gran diversidad de grupos sociales; estos conceptos de dispersión del poder político entre grupos autónomos y dispersión de los centros de decisión política fueron, y continúan siendo, los más influyentes conceptos políticos en los países occidentales desde el siglo XX. ${ }^{19}$

\footnotetext{
17 lbid., p. 493.

18 Abrisketa, Joana. "Genocidio". En Diccionario de acción humanitaria y cooperación al desarrollo. HegoaIcaria. Con sulta: diciembre 2008. http://dicc.hegoa. efaber.net/listar/mostrar/117

19 Bogdanor, Vernon ed. "Pluralismo". Enciclopedia de las instituciones políticas. Madrid: Alianza Editorial, 1991, p. 547
} 
Las técnicas pluralistas de acomodación de las diferencias culturales están alejadas radicalmente de los mecanismos de dominación. Estos últimos mecanismos varían en una escala que va desde la posición más extrema en la que la mayoría busca la hegemonía absoluta dentro del Estado, hasta posiciones en las que el grupo dominante busca fortalecer su posición respecto a otros grupos otorgando a los miembros de la mayoría mayor acceso a los recursos de poder político, económico y cultural; o bien situaciones en las que el propósito es mantener el status quo. ${ }^{20}$ Por el contrario, las técnicas pluralistas están orientadas a otorgar autonomía a los grupos étnicos minoritarios.

Si los grupos culturales diferenciados y los mecanismos pluralistas están reconocidos legalmente se considera que existe un pluralismo formal. Si los grupos no son reconocidos como tales, pero los mecanismos institucionales existen realmente de tal manera que se les da la posibilidad de expresarse, sin designarlos específicamente, existe un pluralismo informal. ${ }^{21}$

Actualmente, las ciencias sociales han establecido que la diferencia como derecho afecta a toda clase de grupo social con una determinada identidad distintiva que se moviliza en torno a ella para reivindicar su reconocimiento. ${ }^{22}$ Es considerado legítimo que los grupos étnico-culturales, adicionalmente a su participación en algunas instituciones comunes obligatorias, sean libres de participar en otras instituciones alternativas o exclusivas para propósitos particulares, de tal manera que pueden, como una nación subordinada o minoritaria, fijar sus propias normas, expresar libremente su cultura con el apoyo público, y promover con el apoyo del Estado procesos alternativos de construcción nacional (nation building) en sus respectivos territorios.

En este sentido las Constituciones se pueden clasificar en términos del balance entre las fuerzas centralistas o descentralistas que se manifiestan en la estructura del Estado, es decir, las Constituciones pueden tender hacia políticas asimilacionistas o mecanismos pluralistas.

De esta manera, una Constitución unitaria-centralista se da cuando los poderes de gobierno están organizados bajo una autoridad central que ejerce la actividad legislativa del Estado (u otras funciones propias éste). A diferencia de ésta, los mecanismos pluralistas democráticos tienden a la descentralización; un mecanismo clásico de descentralización es el establecimiento de un Estado federal en el que los poderes de

\footnotetext{
20 "In states where the controlling elite have extreme domination position and have sufficient force, they can expulse the minority directly or indirectly creating intolerable living conditions for the minority. There may even be genocide (...) In the standard domination situation there are noticeable departures from the equality and non-discrimination principles. There is equally domination in the form of an attempt to freeze existing power patterns. Forced assimilation is domination, whether this is implemented by the provision only of majority-determined linguistic schooling or religious facilities, or by state preservation only of majority cultural symbols. It is domination in the sense of maintaining the current political, economic, and cultural predominance of the majority group, and domination in that it denies alternatives to other groups whose members are subjected to enforce integration (...)The dominant groups' elite may adopt a strategy of destroying minority groups motives for large scale political change by en ging pol stability through altering disadvantageous patterns of imbal ance in the economic and cultural spheres as between different group members. In such an event legal arrangements will be used to improve the position of group members of the minority groups whose economic and social position has been selected for upgrading ('affirmative action')." Palley, Claire. "Constitutional Law and Minorities". Minority Rights Group. International Report. Núm. 36. London, 1978, pp. 8-9

21 Palley. Op. cit., p. 6.

22 Beltran Antolin, Joaquín. "El nou valor de la diferencia". En ROS HIJAR, Adela edit. Interculturalitat: bases antro pològiques, socials i polítiques. Universitat Oberta de Catalunya, 2003, p. 45.
} 
gobierno están distribuidos entre la autoridad central y los gobiernos regionales o locales. ${ }^{23}$

Las previsiones constitucionales federales buscan reducir la desigualdad a un grado ínfimo. Se entiende que la diferencia de trato del Estado hacia las unidades federales debiera tender a la igualdad entre ellas; esta posición, sin embargo, es criticada por que su estructura jurídica no basta para contrarrestar eficazmente las diferencias sociales de hecho -diferencias culturales centralmente- que caracterizan a los distintos pueblos o naciones componentes del Estado. ${ }^{24}$ Esto supone un déficit democrático ya que en la práctica se tienen unidades privilegiadas por el Estado, aunque en menor medida que en el Estado centralista.

Un intento de superación de este escollo para la democracia se puede encontrar, entonces, en la constitución de democracias plurinacionales, más específicamente en la distribución del poder político de tal manera que se constituya un Estado multinacional federal, un Estado con un federalismo asimétrico.

La ciencia política postula cuatro soluciones clásicas en la búsqueda de cierta acomodación política del pluralismo nacional interno: los sistemas federales, el consocialismo, los procesos de devolución política, y la secesión. ${ }^{25}$

\section{1.- Políticas de acomodación de las diferencias étnico-nacionales.}

Las políticas de acomodación permiten plantear de manera no violenta y negociada las contradicciones etnonacionales con la finalidad de fortalecer la estabilidad democrática de un Estado plurinacional. Se buscan con estas políticas algunas formas de solución del problema territorial de distribución del poder mediante formas no mayoritarias (no dominantes) de descentralización del poder político, que desechen las políticas de eliminación para implementar políticas de acomodación étnica, superando el modelo del Estado nacionalizador. Estas políticas son: el federalismo, la democracia consociativa y la secesión democrática. ${ }^{26}$

a) Federalismo: consiste en la distribución territorial del poder y la descentralización mediante la creación de unidades cada una de las cuales tiene facultades de decisión particulares y cuenta con poder legislativo, ejecutivo y judicial propios; puede ser definido mediante la fórmula self rule - shared rule (autogobierno más cogobierno). El federalismo corrige, mediante la creación de un Estado compuesto, las desventajas que acarrean la inexistencia de derechos colectivos o de grupo, la ausencia de autogobierno y la participación democrática.

Desde el punto del tratamiento de la diferencia étnico-nacional los federalismos pueden ser: federalismo simétrico, en Estados-nación con una homogeneidad cultural considerable (como por ejemplo Alemania o EE.UU.); y federalismos asimétricos en Estados plurinacionales (como Canadá, Suiza, Bélgica, España). En el federalismo

\footnotetext{
23 Una información detallada sobre estas técnicas puede ser encontrada en Palley. Op. Cit.

${ }^{24}$ Partiendo desde la realidad del Estado Español, OBIETA comenta: En los Estados autonómicos se da también una desigual dad entre los pueblos en el Estado multinacional... la autonomia concedida a los diversos pueblos no suele llegar nunca al extremo de considerarlos a todos iguales entre sí, sino a lo sumo al reconocimiento de su existencia oficial y a la concesión de determinados derechos o facultades en materias muy concretas y específicas. La prevalencia indiscutible de un pueblo privilegiado suele seguir siendo nota destacada en estos Estados. De Obieta Chalbaud, José. El derecho humano de autodeterminación de los pueblos. Madrid: Tecnos, 1993, p.127.

${ }_{25}$ Para un enfoque más amplio sobre el federalismo en las democracias plurinacionales puede verse el libro: Requejo Coll, Ferran Coord. Democracia y Pluralismo Nacional. Barcelona: Ed. Ariel Ciencia Política, 2002.

${ }^{26}$ En este trabajo resumo las ideas de Maíz. Op. Cit., p. 495; y de Requejo. Op. Cit.
} 
asimétrico las unidades federales coinciden con la distribución territorial de los grupos culturales nacionales o regionales existentes en el país; es decir, se constituyen unidades federales allí donde existe un grupo cultural/nacional diferenciado. En palabras de Maíz, el federalismo asimétrico, real y democrático, constituye hasta la fecha el más contrastado modelo de regulación de conflictos nacionales que permite ensayar la difícil síntesis de autonomía política, solidaridad, confianza inter-territorial y democratización $[\ldots] .{ }^{27}$

Las cualidades positivas del federalismo asimétrico para la organización democrática del Estado vienen siendo reconocidos, al menos en España y en Canadá, desde diversas corrientes teóricas a veces opuestas. Por ejemplo, desde una posición conservadora, Herrero y Rodríguez, señala que este tipo de federalismo define a la situación de organización del Estado, a la distribución geográfica del poder, en la que las unidades federadas son cualitativamente heterogéneas entre sí, mantienen distintos signos de identidad (cultural), diversos grados de autogobierno y diferentes relaciones con las instituciones federales; su aplicación, a pesar de algunas deficiencias ha sido positiva. Este autor sostiene, sin embargo, que el federalismo asimétrico no es una panacea económico-social ni una consecuencia del principio democrático, sino que constituye solo el reconocimiento de una realidad social diversa en la que las diferencias culturales nacionales no suponen el reconocimiento de una condición mejor, sino de una identidad distinta. ${ }^{28}$

Enfoques más tendientes hacia posiciones progresistas identifican, como hemos indicado, que el federalismo asimétrico es una consecuencia de los principios democráticos, a su vez que es requisito para que una sociedad política pueda ser considerada como un sistema democrático; además que constituye un fundamento del desarrollo económico y social.

a) Consociación: la democracia consociacional es una alternativa no mayoritaria para resolver la plurinacionalidad en contextos muy variados. Los sistemas consociativos comprenden desde un gobierno de gran coalición que incorpore a los partidos políticos representantes de las minorías, hasta un alto grado de autonomía para cada grupo en asuntos internos, pasando por el veto mutuo o gobierno de mayoría concurrente en asuntos constitucionales 0 la proporcionalidad en el reclutamiento de élites y funcionarios.

b) Secesión democrática: Es la acción colectiva por la que un grupo intenta independizarse del Estado en el que se encuentra integrado, mediante la separación de parte del territorio del Estado existente. En su forma no violenta

\footnotetext{
27 "es una alternativa más flexible y renegociable, y a la vez más cooperativa y democrática que la aparición de Estados independientes nacionalizadores o no. Pues el federalismo sitúa como centro la pluralidad y la riqueza de la multinacionalidad en convivencia pacífica, generando mediante la solidaridad y tolerancia institucionalizadas una diversidad democrática mucho más rica" (...) Para aquellos en los que las minorías nacionales no se encuentren espacialmente concentradas, existe una escasamente practicada variedad de federalismo, el corporativo,... atribución de los individuos de la posibilidad de declarar a qué nacionalidad autónoma se adscriben (Estonia 1920, Chipre 1960)" MAíZ, Op. Cit. P. 498. Maíz indica que las características de los modelos federales son: Una norma constitucional o al menos superior a la ley ordinaria en la que se regulen los poderes legislativo, judicial y ejecutivo propios de unidad federal y sus competencias. Órganos políticos propios, especial mente poder legislativo, mediante un parlamento que refleje una correlación de fuerzas políticas eventualmente diferenciada del Estado. Participación en los órganos centrales del Estado a través de mecanismos varios: Una segunda cámara federal, conferencias de cooperación, federalismo de ejecución, etc. Órgano judicial de resolución de conflictos (Tribunal Constitucional) entre el Estado central y los federados. p. 497.

28 Herrero y Rodríguez de Miñón, Miguel. "El debate sobre el federalismo en España". En Revista Valenciana d’Estudis Atinomics. Núms. 39-40, pp. 110-121
} 
es una modalidad de acomodación que puede plantearse de forma pacífica y democrática si fracasan las fórmulas de federación o la consociación.

\subsubsection{Modelos territoriales de organización del Estado.}

Las citadas políticas de manejo de las diferencias culturales se traducen en los respectivos modelos territoriales de organización del Estado. Al igual que las políticas de manejo de las diferencias étnico-culturales, estos modelos se distinguen tomando en cuenta el grado de centralización de sus sistemas político-administrativos. Así, se pueden distinguir entre Estados unitarios y compuestos. La expresión máxima de los Estados compuestos y de la división territorial del poder político es la Confederación, una alianza de unidades estatales soberanas más o menos circunstancial; luego están los Estados federales y los Estados regionales o autonómicos. En el polo opuesto se encontrará el Estado unitario centralizado en el que no cabe formalmente una autoridad independiente del gobierno central.

El Estado unitario se caracteriza por la existencia de un único centro de poder que adopta todas las decisiones políticas y detenta el monopolio de la creación de normas jurídicas, aplicables en todo el territorio y a todos los ciudadanos. Sin embargo, en el Estado unitario es frecuente que se presente alguna forma de descentralización administrativa de baja intensidad organizada sobre unidades territoriales pequeñas (municipios o equivalentes), ya que no existe un Estado unitario puro. Se pueden distinguir tres modelos: el Estado unitario altamente centralizado propio de regímenes autoritarios no democráticos; el Estado unitario centralizado al estilo de Francia, Suecia y Finlandia; y el Estado unitario ajustado, capaz de algún grado de descentralización para descongestionar la administración pública, como Reino Unido y Francia como ejemplo. ${ }^{29}$

El Estado federal, se ha asociado desde 1945 con los países más grandes del mundo como Estados Unidos, la antigua Unión Soviética, India, Nigeria, Brasil, Canadá y Australia, lo que puede explicarse como que el federalismo es el acuerdo constitucional más adecuado para afrontar con éxito las diferencias económicas y sociales que conllevan las grandes extensiones. Es un modelo de organización territorial que se adapta bien a Estados con gran diversidad cultural.

La Confederación, es una fórmula de unión de Estados en desuso desde finales del siglo XIX, sin embargo, algunos ven en esta forma los planteamientos federalistas actuales y los debates suscitados sobre la Unión Europea. La Confederación tiene su origen en un pacto internacional que da lugar a una unión de Estados con carácter permanente. A diferencia del modelo federal, aquí los Estados que componen la unión mantienen su independencia, su identidad como sujetos soberanos y entre ellos priman las relaciones de coordinación.

El Estado regional y autonómico, es un modelo de Estado unitario que crea unidades territoriales subestatales con poderes políticos propios por razones administrativas, históricas y democráticas. Estas son unidades territoriales políticamente autónomas, pero a partir de una sola soberanía. En el Estado autonómico la regulación de la autonomía política está contenida en la Constitución y en los Estatutos de Autonomía, en el caso de España, que son los que perfilan la distribución territorial del poder del Estado.

29 López Trigal y Benito Del Pozo. Op. Cit., p. 224. 


\section{2.- Descentralización política y pueblos indígenas.}

Es cierto, como se ha indicado que la nación es una construcción humana, y -como indica Ibarra Palafox- las grandes naciones son construcciones del Estado. ${ }^{30}$ El Estado nacional debe ser entendido como una serie de arreglos y acuerdos entre los integrantes de la sociedad política, sobre ciertos valores y principios que definen la identidad nacional. En este sentido el Estado es una institución, es decir una serie de mecanismos, de conciertos, de acuerdos. Una vez creada o constituida la identidad nacional, el Estado intentará que sea asumida por todos los que se encuentran en su espacio territorial.

El citado autor comenta, siguiendo la orientación de la teoría de la justicia de Rawls, que el proceso de construcción de una sola cultura nacional (o cultura dominante) por parte del Estado, si no toma en cuenta en dicho proceso a las culturas de sus minorías etno-culturales no satisface el primer principio de justicia, es decir, no está otorgando garantías suficientes para que las minorías conserven y reproduzcan su cultura; en este proceso el Estado ignora a las culturas o las destruye.

En este sentido, el principio de justicia Rawlsiano debería reformularse en estos términos: "[...]para que todos, incluidos los integrantes de las minorías etnoculturales gocen de un esquema adecuado de derechos y libertades básicas que sean compatibles con los derechos y libertades de los otros, se requiere que se construya una nación multicultural que integre a las culturas minoritarias, pues es solo a través de su cultura particular que los miembros de las minorías pueden ejercer sus derechos y libertades". ${ }^{31}$

Hay que recalcar que la búsqueda de un modelo adecuado para acomodar las diferencias culturales de los pueblos indígenas en un marco constitucional democrático participativo no es una tarea imposible; esta exploración puede servirse de los modelos constitucionales de acomodación de las diferencias culturales a los que nos hemos referido anteriormente, pero debe buscar creativamente una fusión de modelos o nuevos diseños constitucionales. Es de vital importancia tomar en cuenta que elementos culturales diferenciados (como la lengua, la historia, las instituciones jurídicas tradicionales, el sentimiento nacional en general) de las minorías nacionales o los pueblos indígenas deben ser incorporados en los momentos fundacionales de un Estado o en las reformas que se dan a los documentos fundacionales.

Estos grupos culturales diferenciados con sus diferencias de expresiones de herencias culturales propias son una de las bases, o el principal soporte, en las que se asienta la autoafirmación de una identidad colectiva territorial, ${ }^{32}$ en otras palabras, son estos grupos culturales la plataforma sobre la que se asienta el Estado multinacional en la práctica (en la realidad constitucional), por lo tanto la Constitución política debe dar cabida a todos los pueblos en los momentos fundacionales del Estado para no correr el peligro de convertirse en un instrumento fundador de un Estado ilegítimo, que instaure un remedo nocivo de democracia de baja intensidad, en un instrumento jurídico que legitime mecanismos de dominación ilegítimos.

Desde las consideraciones de participación democrática de todos los pueblos en las constituciones de Estados en los que existe importante presencia de grupos étnico-

\footnotetext{
30 Ibarra Palafox, Francisco. Minorías etnoculturales y Estado nacional. México: Instituto de Investigaciones Jurídicas UNAM, 2005.

31 lbid., p.133.

32 Ruiz-Rico, Gerardo. "Introducción metodológica sobre el estudio de la cultura por el Derecho constitucional". En Ruiz Rico, Gerardo y Nicolás Pérez Sola. Constitución y cultura. Retos del Derecho constitucional en el siglo XXI. Junta de Andalucía, Tirant lo Blanch. Valencia, 2005, pp. 9-32, p. 24.
} 
nacionales diferenciados, una de las formas, o la única forma de garantizar los principios de justicia básicos, es la formación de Estados multinacionales. El Estado tiene que participar de manera activa en esta construcción con la finalidad de acomodar las diferencias culturales.

De hecho, la situación de cada grupo cultural amerita un tratamiento determinado, no se puede generalizar las soluciones como un modelo aplicable a todos los casos. Pero se puede afirmar que en el caso de los pueblos indígenas una forma novedosa es el reconocimiento y constitución de formas autonómicas indígenas.

Estas formas autonómicas pueden variar su contenido, pero por lo general consistirían en un régimen político-jurídico acordado entre el Estado y los pueblos indígenas mediante el cual se crea un sistema especial dentro del propio Estado que configura un gobierno propio (autogobierno) para los pueblos indígenas, mediante el cual éstos se encuentren en condiciones de escoger a sus autoridades, ejercer determinadas competencias legalmente atribuidas para regular su vida cultural, así como para administrar sus propios asuntos. Es decir, se trata de distribuir el poder hacia abajo, hacia los pueblos indígenas, de crear autonomías que sean capaces de ejercer poder en sus materias delegadas y posibilitar un control de abajo hacia arriba de las decisiones del Estado. Una propuesta interesante en este sentido ha sido ensayada teóricamente por Ignacio Cremades. ${ }^{33}$

En estas formas autonómicas, los pueblos indígenas deben tener competencias para normar aquellos asuntos que les permitan reproducir su cultura societal. Un régimen autonómico justo debería presentar los siguientes elementos: ${ }^{34}$

a) Un conjunto de derechos que garanticen la igualdad de los miembros de los pueblos indígenas frente a la sociedad dominante para el ejercicio de sus derechos y libertades. Iguales derechos a los de la sociedad dominante, por ejemplo, derechos lingüísticos amplios.

b) Competencias autonómicas pactadas con el Estado para reproducir la cultura societal de los pueblos indígenas, competencias sobre educación, tierra, recursos naturales, y también normas de carácter general (facultades legislativas o cuasilegislativas), y disposiciones tendientes a hacer cumplir esas normas de carácter general (facultades administrativas o cuasiadministrativas).

c) Base territorial que permita el sustento y el desarrollo. Territorios suficientes para que los pueblos indígenas reproduzcan su cultura y mantengan una igualdad mínima de oportunidades socioeconómicas.

d) Autogobierno, que los pueblos indígenas ocupen primordialmente los puestos públicos (plazas o vacantes de funcionarios públicos) que se abran en sus autogobiernos, según la igualdad de oportunidades. Debe entenderse que la autonomía es una forma de ejercicio de la autodeterminación.

\section{4.- Teoría y crítica de la constitución: derecho constitucional y etnicidad.}

\footnotetext{
${ }^{33}$ Cremades, Ignacio. "Etnicidad y Derecho: aproximación jurídica al Derecho indígena de América", En Ordoñez Cifuentes, José E. R Coord. Etnicidad y Derecho un dialogo postergado entre los científicos sociales. V Jornadas Lascasianas. Tercera edición. México: Universidad Autónoma de México, 1996, pp. 141-213.

34 Ibarra. Op. Cit., p. 135.
} 
Desde un punto de vista dogmático jurídico, con carácter abstracto y general, toda Constitución puede definirse como un conjunto de normas escritas y consuetudinarias, dotadas generalmente de rango singular, que regulan la organización de poderes y definen los derechos y deberes de los particulares. ${ }^{35}$ Sin embargo, esta definición dogmática legal es superficial e incompleta, por lo que para efectos de una correcta investigación debemos ir un poco más allá, hacia la esencia de la Constitución. Hemos indicado que un análisis de la constitución que aspire a ser completo, que se haga desde un punto de vista científico holístico, y más aún sociológico, debe de tomar en cuenta el análisis de la realidad constitucional, compuesta ésta por el marco en el que están los campos jurídicos y extrajurídicos (el campo de la constitución escrita y los campos sociales-políticos-culturales).

Aunque criticada por buena parte de la dogmática jurídica liberal, el concepto de constitución de Lassalle puede ser de gran ayuda al momento de entender la ubicación de la Constitución normativa en el entramado social, en la realidad constitucional. La Constitución, decía este autor, es en esencia una suma de los factores reales de poder que rigen en un país o en una sociedad política concreta denominada Estado "[...] se cogen esos factores reales de poder, se extienden en una hoja de papel, se les da expresión escrita, y a partir de ese momento, incorporados a un papel, ya no son simples factores de poder, sino que se han erigido en derecho, en instituciones jurídicas, y quien atente contra ellos atenta contra la ley y es castigado". ${ }^{36}$ Existe por lo tanto una Constitución real o concreta que puede estar fuera de la norma escrita, de la hoja de papel. Es esta Constitución real, la constitución en sentido material como la llamaría Mortati, la que influye de gran manera, la que determina, y en algunos casos rige en realidad las relaciones de los individuos con el Estado, y de los grupos étnicos con el Estado.

Los factores de poder, el llamado poder realmente existente que da forma a la Constitución, establecen relaciones de dominio y hegemonía entre sus componentes mediante la ley constitucional por lo que se dice que el Derecho en general y el Derecho constitucional en particular tienen una naturaleza relacional. En otras palabras, las relaciones de los grupos de poder real son elevadas al rango de ley mediante la Constitución; la Constitución hace que estas relaciones tengan una traducción jurídica, con todos los atributos que la ley tiene. Una de las funciones del Derecho constitucional es la de ser un Derecho procesal político ${ }^{37}$ que determina legalmente los mecanismos en los cuales se van a desenvolver las relaciones de confrontación entre los diversos proyectos políticos de los grupos de poder presentes en un Estado.

La Constitución establece, entonces, relaciones legales entre grupos, y cómo estas relaciones van a desenvolverse, procesarse para que no se rompa la unidad del proyecto político denominado Estado-nación. Esta situación relacional se hace más complicada cuando se trata de la multiculturalidad presente en casi todos los Estados del mundo. En el Estado en general, y principalmente en los Estados postcoloniales, existen grupos -raciales, lingüísticos, religiosos, de casta, o grupos nacionales sin Estado, es decir, grupos étnicos que son excluidos de la elaboración de la Constitución y no tienen el control de la maquinaria política del Estado. Por lo tanto, estamos ante la

\footnotetext{
35 Escuin Palop, Vicente. Elementos de Derecho Público. Madrid: Tecnos, 1999, p. 37.

36 Lasalle, Ferdinand. ¿Qué es una Constitución? Barcelona: Ariel, 1997, p.92

37 Pérez Royo, Javier. Curso de derecho constitucional. Marcial Pons. Segunda Edición. Madrid, 1995, p. 55.
} 
existencia de una Constitución real en la cual un factor de poder importante no es tomado en cuenta.

Los grupos culturales/étnicos privilegiados del Estado son los que hacen prevalecer su proyecto nacional, su propio proyecto de nation-building, ${ }^{38}$ con perjuicio de los grupos étnicos dominados o no privilegiados. De esta manera, el proceso político que ordena la constitución en estos Estados postcoloniales es un proceso viciado por violar las garantías políticas de participación democrática primigenia, o excluir de su fundación, a uno o varios grupos étnicos (o nacionales) que debieran estar presentes en el proyecto constituyente originario o al menos ser considerados en él de manera importante por el grupo dominante.

Desde un punto de vista de análisis cultural de la Constitución Política de un Estado se puede decir que las constituciones que no toman en cuenta a los grupos étnicos minoritarios o no dominantes no son constituciones democráticas (o simplemente que en dichos Estados no existe constitución sino esquemas legales de dominación) ya que son documentos constitucionales que predicen el resultado del enfrentamiento político a favor de un determinado grupo étnico-cultural, manipulan y falsean el proceso político a su favor.

En los países de América del Sur se han dado procesos de construcción nacional basados en una ingeniera social conscientemente planificada. Las elites políticas han intentado construir una "nación" involucrándose en procesos conscientes de control social de los grupos étnicos, combinando un régimen político autoritario y negándose a hacer concesiones de al menos un cierto grado de autodeterminación a las minorías étnicas. Para que estos procesos de construcción nacional funcionen, las constituciones han adoptado varios procedimientos y arreglos predeterminados que se pueden seguir en la historia.

Como ejemplo se pueden citar los modelos, identificados por Yrigoyen ${ }^{39}$, que tienen como objetivo la dominación del indígena, mediante el despojo de sus territorios, el aseguramiento de su subordinación política, y su anulación cultural. Tales modelos de tratamiento son diseñados desde las primeras constituciones históricas americanas (incluyendo la Carta de Cádiz de 1812). Dichos modelos de dominación constitucional pueden ser resumidos en cuatro. El primero, el modelo segregacionista colonial de tutela federal de naciones domésticas, aparece con la Constitución de los Estados Unidos de América de 1787, orientada a la domesticación de las naciones indias no sometidas, con las que la Corona Inglesa, y luego la Unión habían firmado tratados, como los que firmaban con naciones extranjeras. El segundo modelo, el modelo liberalasimilacionista, diseñado por la Constitución de Venezuela de 1811, la primera del proceso de independencia de América Latina, que busca finalizar el régimen legal diferenciado y lo que quedaba de autoridad colectiva indígena que el sistema de

\footnotetext{
38 "Recent social engineering activities have occurred in the new nation states in Asia and Africa. The political elites attempt to build a "nation" consciously trying in activities of social control. They tried to induce and regulate social change by recon structing their political and economic institutions to embody and to promote innovation and to enhance their efficiency by centralisation. They engaged in conflict management. They tried to induce national integration by attempting to control indi viduals' subjective loyalties and to redirect these to a new nation state so as to downgrade local loyalties. They have tried to create a new consensus. They sought to create a new ideology. They featured selected national symbols (flag, national dress, national traditions). They tried to use language to draw the nation together. They tried to direct the economy and national wealth for national objects. The approach was usually authoritarian". En Palley, Claire. Op. Cit.

39 Yrigoyen Fajardo, Raquel. "Hitos del reconocimiento del pluralismo jurídico y el derecho indígena en las políticas indigenistas y el constitucionalismo andino", En BERRAONDO, Mikel coord. Pueblos Indígenas y derechos humanos. Bilbao: Universidad de Deusto, 2006, pp. 537-567.
} 
gobierno indirecto y pluralismo subordinado de la Colonia permitían. El tercero, el modelo constitucional misionero-civilizador, se puede ver en las constituciones de Colombia (entonces Nueva Granada) de 1811 y de Cádiz de 1812, todavía bajo la monarquía española, se caracteriza por un programa de conversión religiosa y civilización de los indígenas infieles/incivilizados, bajo tutela eclesial o estatal, buscando el sometimiento de las naciones indígenas aún no colonizadas, su sedentarización misiones o reducciones con la finalidad de ganar territorio para los nuevos Estados. Finalmente, un cuarto modelo, el de integracionismo constitucional pluralista de finales de siglo $\mathrm{XX}$, caracterizado por el reconocimiento por parte del Estado, hecho bajo inspiración del constitucionalismo social, del sujeto colectivo indígena y derechos especiales. Dicho reconocimiento solo se dirige a las comunidades o etnias y no a los "pueblos" por el componente político que entraña dicha consideración con respecto al derecho de autodeterminación; mantiene el ideal del Estado-nación y el monismo legal, sin embargo, se reconocen "costumbres" y algunas formas subordinadas de justicia indígena. Este último modelo estaría marcando la emergencia de un horizonte pluralista, y esta ejemplificado con las constituciones de Guatemala (1985), Nicaragua (1987), Brasil (1988), Colombia (1991), Perú (1993), Paraguay (1992), México (1992-2001), Bolivia (1994-2003), Ecuador (1998) y Venezuela (1999).

La constitución es el Derecho del Estado, es la manifestación política de las fuerzas sociales que fundan el Estado en un momento histórico determinado, que establece quien es el pueblo fundador de dicho Estado y le otorga derechos y le impone deberes, que organiza y distribuye el poder entre sus instituciones políticas, que determina una serie de normas básicas para la distribución territorial del poder. Así, pueblo, Estado y territorio son definidos claramente por la constitución. Un estudio de la constitución que trate de engarzarse con el multiculturalismo debe tener en cuenta estos elementos, debido a que ellos son campos en disputa por los diversos proyectos políticos presentes en el Estado.

Tomando en cuenta un análisis cultural del Estado postcolonial con presencia de diversos grupos étnico-nacionales, es decir grupos culturales con diversas concepciones de lo político, del Estado, y diversos proyectos nacionales; se tiene que tomar en cuenta en un estudio del constitucionalismo y la multiculturalidad cuáles son las propuestas, los intereses, los proyectos de estos grupos respecto a la constitución política del Estado, los proyectos en disputa en los campos constitucionales, y las tensiones existentes en los diversos enfoques culturales sobre lo que debiera ser una Constitución, sobre su diseño y contenido normativo.

El constitucionalismo es la teoría del Estado constitucional en la que las teorías liberales son la concepción dominante. El multiculturalismo son las propuestas teóricas que se hacen sobre la sociedad multicultural. Así, un estudio del constitucionalismo y el multiculturalismo debe de tomar en cuenta, por un lado, cuáles son las propuestas multiculturalistas que atañen a la teoría de la constitución, cuáles son las ideas sobre el multiculturalismo que influyen en la redacción de las constituciones políticas y, por otro lado, cuáles son los factores de la realidad concreta que influyen o determinan la constitución política del Estado. El primer propósito es un estudio del discurso político convertido en ley constitucional, el segundo es un estudio de la realidad constitucional.

La bibliografía sobre multiculturalidad y derechos indígenas parte de un error fundamental, presupone que el Estado ya está constituido de antemano y es intocable, que en la investigación no se puede ir más allá de la letra de la Constitución, que no se puede ir en la propuesta en contra de la Constitución establecida, que lo que hay que hacer es estudiar las constituciones tal y como están y, a lo sumo, proponer algunas 
medidas de reforma. Dicha bibliografía cae en lo que los críticos del positivismo jurídico han llamado el "fetichismo de la ley".

Para abordar correctamente el estudio del discurso jurídico constitucional y de la realidad constitucional desde una posición que supere el clásico enfoque liberal conservador y el positivismo ultramontano se debe adoptar necesariamente una postura crítica del sistema legal y de la doctrina jurídica predominante que avance hacia la ampliación de la democracia y la justicia social.

Estos son los elementos que pueden ayudar a articular una teoría crítica del derecho como crítica democrática y comprometida con el derecho desde y de los de abajo, junto con la consideración de que el Derecho y la llamada "ciencia jurídica" que despliega una teoría legal determinada asumen, ambos, los discursos políticos determinados y las construcciones ideológicas particulares de un grupo social, de un grupo con intereses políticos, económicos y culturales específicos. Algunos de estos elementos teóricos han sido desarrollados, entre otras escuelas, por la teoría crítica del Derecho o la llamada escuela de los Estudios Legales Críticos. ${ }^{40}$

Aporta en este punto la crítica al imperialismo histórico y la propuesta sobre el Constitucionalismo consuetudinario de James Tully respecto al constitucionalismo moderno. Este autor reprocha al constitucionalismo moderno porque excluye y suprime la diferencia cultural al definir al pueblo soberano como una comunidad o grupo de individuos homogéneos que voluntaria y razonadamente establecen una Constitución. El constitucionalismo moderno ignora el pluralismo cuando argumenta que las constituciones se crean en momentos fundacionales que son una condición previa para la democracia, pero no son parte de ella. El constitucionalismo moderno desconoce la diversidad cultural cuando argumenta que las instituciones políticas y jurídicas que defiende son una consecuencia de un estadio específico, superior, de desarrollo humano social y económico, y cuando identifica a cada Estado con una y sólo una única nación que tiene una autoridad central y uniforme para efectos de su estabilidad política y de su orden interno. ${ }^{41}$

Estas contradicciones fundamentales del constitucionalismo moderno con los valores de la democracia y el pluralismo, inspiran a Tully la necesidad de reinterpretar el constitucionalismo moderno para sacar a luz los aspectos de la construcción histórica del pensamiento jurídico y político moderno. Desde hace 400 años, en el pensamiento político y jurídico anglo europeo hay dos perspectivas: una perspectiva moderna europea, masculina, blanca, y una perspectiva de derecho consuetudinario, sensible a la diferencia cultural. Su propuesta es fijarse más en el constitucionalismo consuetudinario, es de estudiar, por ejemplo, las convenciones constitucionales entre los grupos indígenas y la Europa imperial para hallar nuevas interpretaciones del lenguaje del constitucionalismo moderno, tendientes a un diálogo intercultural en el cual ciudadanos soberanos negocian acuerdos sobre formas de asociación, de acuerdo con las convenciones de mutuo reconocimiento, consentimiento y continuidad.

Estas tres convenciones -mutuo reconocimiento, consentimiento y continuidad- son los criterios normativos básicos del constitucionalismo de derecho consuetudinario. Mediante la convención del mutuo reconocimiento se exige que las partes de un debate

\footnotetext{
40 Para un resumen de esta última escuela puede verse: PRÍVÁN, Jíri. "Sharing paradigms? Critical legal studies and the socio logy of law". En BANAKAR, Reza y Max TRAVERS. An introduction to law and social theory. Hart Publishing, 2002.

41 Estas son las ideas que, según Bonilla. Op. Cit., p. 87, resumen la critica que Tully hace al constitucionalismo moderno.
} 
constitucional se consideren recíprocamente iguales en el proceso de diseño de las instituciones políticas y jurídicas. El consentimiento requiere que todas las decisiones adoptadas en el diálogo constitucional sean el producto del libre albedrío. La continuidad se refiere a que, si no se llega a un acuerdo, las culturas de quienes participan en las conversaciones constitucionales no deben sufrir transformación.

Para el constitucionalismo de derecho consuetudinario no hay una metanarrativa que esté por encima y pueda suplantar a las narrativas de cada una de las culturas que sostienen un diálogo constitucional. Cada cultura que participa en la conversación debe poder hablar su propio "lenguaje", cada cultura se compromete y se identifica con la asociación constitucional -con el contrato político social- en la medida en que se reconozcan sus perspectivas y éstas se vean reflejadas en ella. El progreso, se obtiene entonces cuando se celebran efectivamente diálogos interculturales, y cuando éstos crean, reconocen y acomodan la diversidad cultural. ${ }^{42}$

\section{BIBLIOGRAFÍA}

Abrisketa, Joana. "Genocidio", En Diccionario de acción humanitaria y cooperación al desarrollo. Hegoa-Icaria.

Consulta: diciembre de 2008 <http://dicc.hegoa.efaber.net/listar/ mostrar/117>.

Beltrán Antolín, Joaquín. "El nou valor de la diferencia". En Ros Híjar, Adela edit. Interculturalitat: bases antropològiques, socials i politiques. Universitat Oberta de Catalunya, 2003.

Berger, Mark T. "From nation-building to state-building: the geopolitics of development, the nation-state system and the changing global order". Third World Quarterly. Volumen 27, núm. 1, 2006.

Bogdanor, Vernon ed. "Pluralismo". Enciclopedia de las instituciones políticas. Madrid: Alianza Editorial, 1991.

Bonilla Maldonado, Daniel. La constitución multicultural. Bogotá: Siglo del Hombre, Universidad Javeriana, 2006.

Caminal Badia, Miquel et ál. Manual de ciencia política. Madrid: Tecnos, 1998.

Castells, Manuel. "La Era de la Información". Economía, Sociedad y Cultura: El Poder de la Identidad. Volumen II. Primera edición en español. México: Siglo XXI editores, 1999.

Cremades, Ignacio. "Etnicidad y Derecho: aproximación jurídica al Derecho indígena de América", En Ordoñez Cifuentes, José E. R Coord. Etnicidad y Derecho un dialogo postergado entre los científicos sociales. V Jornadas Lascasianas. Tercera edición. México: Universidad Autónoma de México, 1996.

Escuin Palop, Vicente. Elementos de Derecho Público. Madrid: Tecnos, 1999.

Gargarella, Roberto. "El derecho de resistencia en situaciones de carencia extrema". En Astrolabio revista internacional de filosofía. Núm. 4, 2007.

Garreta Bochaca, Jordi. La Integración sociocultural de las minorías étnicas (gitanos e inmigrantes). Barcelona: Anthropos, 2003.

42 Tully, James. "Strange multiplicity". Constitutionalism in an age of diversity. Cambridge University Press, 1997, pp. 117156. 
Herrero y Rodríguez De Miñón, Miguel. "El debate sobre el federalismo en España". En Revista Valenciana d'Estudis Atonomics. Núms. 39-40.

Ibarra Palafox, Francisco. Minorías etnoculturales y Estado nacional. México: Instituto de Investigaciones Jurídicas, UNAM, 2005.

Kymlicka, Will y Wayne Norman. Citizenship in culturally diverse societies: issues, con texts, concepts. Oxford Univ. Press, 2000.

Lassalle, Ferdinand. ¿Qué es una Constitución? Barcelona: Ariel, 1997.

López Trigal, Lorenzo y Benito Del Pozo. Geografía Política. Madrid: Cátedra, 1999.

Maíz Suárez, Ramón. "Retos contemporáneos de la Política II: Los nacionalismos". En R. Del Águila, et al. Coord. Manual de Ciencia Política. Madrid: Trotta, 1997.

Obieta Chalbaud, José. El derecho humano de autodeterminación de los pueblos. Madrid: Tecnos, 1993.

Palley, Claire. "Constitutional Law and Minorities". International Report. Núm. 30. London: Minority Rights Group, 1978.

Pérez Royo, Javier. Curso de derecho constitucional. Marcial Pons. Segunda Edición. Madrid, 1995.

Príván, Jírí. "Sharing paradigms? Critical legal studies and the sociology of law". En Banakar, Reza y Max Travers. An introduction to law and social theory. Hart Publishing, 2002.

Requejo Coll, Ferran Coord. Democracia y Pluralismo Nacional. Barcelona: Ed. Ariel Ciencia Política, 2002.

Ruiz-Rico, Gerardo. "Introducción metodológica sobre el estudio de la cultura por el Derecho constitucional". En Ruiz-Rico, Gerardo y Nicolás Pérez Sola. Constitución y cultura. Retos del Derecho constitucional en el siglo XXI. Junta de Andalucía, Tirant lo Blanch. Valencia, 2005.

Taylor, Marcus. "From national development to 'growth with equity': nation-building in Chile, 1950-2000". Third World Quarterly. Volumen 27, núm. 1, 2006.

Tully, James; Strange multiplicity. Constitutionalism in an age of diversity; Cambridge Uni versity Press, 1997.

Yrigoyen Fajardo, Raquel. "Hitos del reconocimiento del pluralismo jurídico y el derecho indígena en las políticas indigenistas y el constitucionalismo andino", En Berra Ondo, Mikel coord. Pueblos Indígenas y derechos humanos. Bilbao: Universidad de Deusto, 2006. 